by Sano et al. of approximately 1,500 Myr is the expected result.

Second, this rock, which is essentially a quartzite, has no intrinsic capacity to form apatite by metamorphic reactions following diagenesis. Thus, the apatite present in this rock must be original (formed before 3,850 Myr) unless phosphate-bearing fluids were subsequently introduced metasomatically. Although no apatite has been recognized in the BIF that does not contain graphite inclusions, no apatites with graphite inclusions have been found in the immediately adjacent, encompassing gneisses ${ }^{1,6,7}$.

Sano et al. are concerned that if "the apatites were formed during metamorphism, biogenic carbon could have been introduced". Again, given that the encompassing rocks do not contain graphitic inclusions with isotopically light carbon ${ }^{1}$, this could not have occurred after 3,850 Myr.

"If these apatites were formed 3,800 Myr ago," Sano et al. allow, "graphite inclusions within grains of apatite have also experienced a thermal event of around $600^{\circ} \mathrm{C}$ " (actually $400{ }^{\circ} \mathrm{C}$; see http://oro.ess.ucla.edu/ sjm-nature.html) "about 1,500 Myr ago". They posit that the "isotope composition of the carbonaceous inclusions might have been altered by the event". However, the extremely slow self-diffusion rates of carbon in graphite (less than $10^{-39} \mathrm{~cm}^{2} \mathrm{~s}^{-1}$ at $600{ }^{\circ} \mathrm{C}$ ) precludes significant diffusive carbon-isotope exchange.

Could the isotopically light carbon $\left(\delta^{13} \mathrm{C} ; 35 \%\right.$ o $)$ in the apatite inclusions ${ }^{1}$ be abiogenic? Sano et al. seem to prefer a Rayleigh distillation mechanism that was previously $^{8}$ raised to illustrate the unlikelihood of such a process occurring. However, such a process has not been documented in the geological record, and Sano et al. do not specify how abiogenic carbon of $\left(\delta^{13} \mathrm{C}\right.$ exceeding $10 \%$; ref. 9) could be fractionated by about $30 \%$ o to mimic a biogenic signature. Under metamorphic conditions, the relevant mineral assemblage (quartz, magnetite, pyroxene, amphibole, pyrrhotite, apatite and graphite) coexists with $\mathrm{H}_{2} \mathrm{O}$ bearing fluid containing both $\mathrm{CH}_{4}$ and $\mathrm{CO}_{2}$ (ref. 10). The previous calculations ${ }^{8}$ did not consider the participation of $\mathrm{CH}_{4}$, which mitigates against this type of isotope fractionation because it preferentially partitions ${ }^{12} \mathrm{C}$, leaving a residue that becomes isotopically heavier with time, not lighter ${ }^{11}$. Thus, the role for Rayleigh fractionation proposed by Sano et al. is both improbable and unsupported by their $\mathrm{Pb}$ isotope data for apatite. Finally, Sano et al. imply that the rare-earth-element signatures of apatites can distinguish between a biogenic and abiogenic origin, but there is no basis for such a suggestion in this context.

In conclusion, the data reported by Sano et al. are not pertinent to the formation age of the host apatite and are not relevant to the mode of origin or preservation of the isotopically light carbonaceous inclusions they contain. In our view, the occurrence of this geochemical association in rocks of sedimentary origin is best explained as the product of biological activity ${ }^{1,12}$ more than 3,850 Myr ago $^{1,2}$.

S. J. Mojzsis ${ }^{\star}$, T. M. Harrison*,

G. Arrhenius $\ddagger$ K. D. McKeegan ${ }^{\star}$,

M. Grove

${ }^{\star}$ Department of Earth and Space Sciences,

University of California at Los Angeles,

Los Angeles, California 90095-1567, USA

e-mail:sjm@argon.ess.ucla.edu

$\dagger$ Institute for Pure and Applied Physical Sciences,

University of California at San Diego,

La Jolla, California 92093-0360, USA

$¥$ Scripps Institution of Oceanography,

University of California at San Diego,

La Jolla, California 92093-0220, USA

1. Mojzsis, S. J. et al. Nature 384, 55-59 (1996).

2. Nutman, A. P., Mojzsis, S. J. \& Friend, C. R. L. Geochim. Cosmochim. Acta 61, 2475-2484 (1997).

3. Cherniak, D. J., Lanford, W. A. \& Ryerson, F. J. Geochim. Cosmochim. Acta 55, 1663-1673 (1991).

4. Baadsgaard, H., Lambert, R. S. \& Krupicka, J. Geochim. Cosmochim. Acta 40, 513-527 (1976).

5. Pankhurst, R. J., Moorbath, S., Rex, D. C. \& Turner, G. Earth Planet. Sci. Lett. 20, 157-170 (1973).

6. Thrower, P. A. \& Meyer, R. M. Phys. Status Solidi 47, 11-37 (1978).

7. McGregor, V. R., \& Mason, B. Am. Mineral. 62, 887-904 (1977) 8. Eiler, J., Mojzsis, S.J. \& Arrhenius, G. Nature 386, 665 (1997).

9. Deines, P. \& Gold, D. P. Geochim. Cosmochim. Acta 37, 1709-1733 (1973).

10. Ohmoto, H., \& Kerrick, D. M. Am. J. Sci. 277, 1013-1044 (1977).

11. Mojzsis, S. J. \& Arrhenius, G. J. Geophys. Res. 103, 28495-28511 (1998).

12. Schidlowski, M. Nature 333, 313-318 (1988).

\section{Nicotine withdrawal and road accidents}

Waters et al. ${ }^{1}$ suggested that the effects of nicotine withdrawal increase the chances of an accident at work. The second Wednesday of March is 'No Smoking Day' (NSD) in the United Kingdom. If the 'accident effect' is real, increased numbers of other types of accident would be expected on NSD. I have investigated this possibility by using data from the UK national STATS19 accident reporting system ${ }^{2}$, which records details of personal injury accidents occurring on public roads in which at least one

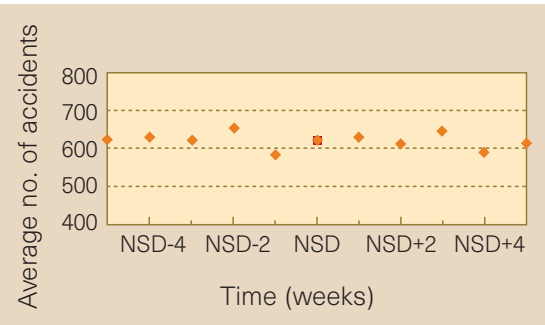

Figure 1 Average number of accidents in 1988-97 on Wednesdays around 'No Smoking Day' (NSD).

road vehicle, or a vehicle in collision with a pedestrian, is involved, and which becomes known to the police within 30 days of its occurrence. Damage-only accidents are not included. The date of the accident is also recorded.

I compared the average number of road accidents occurring over the past 10 years (1988-97) on NSD with the average for the Wednesday before and the Wednesday after NSD. Table 1 shows the means and standard deviations of these measures for NSD week and the weeks before and after it. Paired-sample Student's $t$-tests (one-tailed) did not indicate that there were significantly more accidents on NSD than on the previous Wednesday $(t=-1.36, P=0.10)$ or the following one $(t=-0.39, P=0.35)$.

A visual inspection of the data for the five Wednesdays before and after NSD (Fig. 1) shows no obvious indication that the effects of nicotine withdrawal on NSD led to an increased number of road accidents when compared with the other Wednesdays in February and March. The only feature to stand out is the decrease in accidents between the last Wednesday in February and the first Wednesday in March in 7 of the 10 years examined. No explanation for this effect has been established.

Similar analyses of the severity of accidents and the age and sex of the drivers involved also provide no evidence of an increased number of accidents on NSD.

\section{Jackie Knowles}

Safety and Environment Resource Centre,

Transport Research Laboratory,

Old Wokingham Road, Crowthorne,

Berkshire RG45 6AU, UK

1. Waters, A. J., Jarvis, M. J. \& Sutton, S. R. Nature 394, 137 (1998)

2. Department of the Environment, Transport and the Regions

Road Accidents in Great Britain 1997 (HMSO, London, 1998).

\begin{tabular}{|c|c|c|c|c|c|c|}
\hline \multirow[t]{2}{*}{ Day } & \multicolumn{2}{|c|}{ One week before NSD } & \multicolumn{2}{|c|}{ NSD week } & \multicolumn{2}{|c|}{ One week after NSD } \\
\hline & Average no. & s.d. & Average no. & s.d. & Average no. & s.d. \\
\hline Monday & 593.4 & 63.6 & 598.8 & 84.5 & 627.0 & 99.0 \\
\hline Tuesday & 579.8 & 122.3 & 605.6 & 85.9 & 606.4 & 93.3 \\
\hline Wednesday & 583.2 & 98.2 & 620.7 & 58.4 & 628.1 & 47.8 \\
\hline Thursday & 655.3 & 106.5 & 605.0 & 61.5 & 639.0 & 85.9 \\
\hline Friday & 712.1 & 70.3 & 719.0 & $\begin{array}{l}67.3 \\
6 . . .\end{array}$ & $\begin{array}{l}781.3 \\
\ldots \ldots \ldots\end{array}$ & 90.0 \\
\hline Saturday & 624.3 & 71.8 & 649.0 & 61.4 & 633.1 & 103.6 \\
\hline Sunday & 453.3 & 61.7 & 502.9 & 60.8 & 488.3 & 77.8 \\
\hline
\end{tabular}

